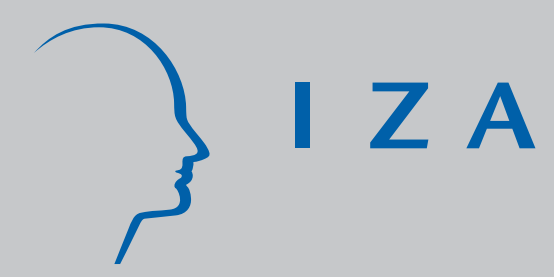

IZA DP No. 3396

\title{
Life-Cycle Equilibrium Unemployment
}

\section{Arnaud Chéron}

J ean-Olivier Hairault

François Langot

March 2008 


\title{
Life-Cycle Equilibrium Unemployment
}

\author{
Arnaud Chéron \\ University of Maine (GAINS) \\ and EDHEC \\ Jean-Olivier Hairault \\ Paris School of Economics (PSE), \\ University of Paris I and IZA \\ François Langot \\ PSE-Jourdan, CEPREMAP, \\ University of Maine (GAINS) and IZA
}

\section{Discussion Paper No. 3396 \\ March 2008}

\author{
IZA \\ P.O. Box 7240 \\ 53072 Bonn \\ Germany \\ Phone: +49-228-3894-0 \\ Fax: +49-228-3894-180 \\ E-mail: iza@iza.org
}

\begin{abstract}
Any opinions expressed here are those of the author(s) and not those of IZA. Research published in this series may include views on policy, but the institute itself takes no institutional policy positions.

The Institute for the Study of Labor (IZA) in Bonn is a local and virtual international research center and a place of communication between science, politics and business. IZA is an independent nonprofit organization supported by Deutsche Post World Net. The center is associated with the University of Bonn and offers a stimulating research environment through its international network, workshops and conferences, data service, project support, research visits and doctoral program. IZA engages in (i) original and internationally competitive research in all fields of labor economics, (ii) development of policy concepts, and (iii) dissemination of research results and concepts to the interested public.
\end{abstract}

IZA Discussion Papers often represent preliminary work and are circulated to encourage discussion. Citation of such a paper should account for its provisional character. A revised version may be available directly from the author. 
IZA Discussion Paper No. 3396

March 2008

\section{ABSTRACT}

\section{Life-Cycle Equilibrium Unemployment}

This paper develops a life-cycle approach to equilibrium unemployment. Workers only differ respectively to their distance from deterministic retirement. A non age-directed search equilibrium is then typically featured by increasing (decreasing) firing (hiring) rates with age and a hump-shaped age profile for employment. Because of intergenerational inefficiencies, the Hosios condition no longer achieves efficiency. We then explore the optimal age-pattern of some policy tools to restore this efficiency. The optimal profile for employment subsidies should increase with age, whereas firing taxes and hirings subsidies would have to be humpshaped. Lastly, we examine the robustness of our results. We show that age-directed recruitment policies cannot exist in equilibrium even if it would have been ex-ante possible, and that introducing endogenous search effort of unemployed workers reinforces our main results.

JEL Classification: J22, J26, H55

Keywords: job search, matching, life cycle

Corresponding author:

Jean-Olivier Hairault

EUREQua

University of Paris I

106-112, Boulevard de l'Hôpital

75647 Paris Cedex 13

France

E-mail: joh@univ-paris1.fr

\footnotetext{
* We thank the participants at the SED congress (Vancouver, 2006), and the IUI (Stockholm, 2006) and Pennsylvania seminars (Philadelphia, 2007) for helpful comments.
} 


\section{Introduction}

Since Oi [1962], labor is conventionally viewed as a quasi-fixed input factor. The hiring process is costly and firms implement labor hoarding strategies: forward looking decisions of hiring and firing depend on the time over which to recoup adjustment costs. A major contribution of the extensively used framework of Mortensen and Pissarides [1994] (MP hereafter) is to provide theoretical foundations to these mechanisms in a overall theory of equilibrium unemployment with matching frictions and wage bargaining. In that context, endogenous hirings and separations depend on expected duration of jobs. Surprisingly enough, the life cycle of workers has not been yet incorporated in equilibrium unemployment models whereas this duration is obviously tightly related to the distance from worker's retirement. This is as much surprising as the relation between the labor supply and the life cycle was already pointed out since the seminal Heckman [1974] and MaCurdy [1981] papers. Seater [1974], Hutchens [1988] and more recently Lunqjvist and Sargent [2002] also emphasized the role played by the life cycle in the search decision of unemployed workers, both from theoretical and empirical standpoints. This paper aims at filling this gap by examining positive and normative issues related to the introduction of the life cycle in the theory of equilibrium unemployment.

Traditionally, the labor market equilibrium is analyzed by taking into account specific labor market institutions like employment protection (Blanchard and Portugal [2001]), unemployment insurance (Lunqvist and Sargent [2004]) or tax system and government (Prescott [2004], Rogerson [2006]). These studies do not recognize the employment differences by age as central. In this paper, we put forward the idea that adopting a life cycle view may enhance our understanding of the labor market equilibrium. Indeed, Figure 1 shows firstly that employment rates differ across ages whatever the country considered. The age-dynamics of employment is hump-shaped: younger and older workers display lower employment rates. Secondly, as can be seen in figure 1, employment rate differences across countries seem to be concentrated at particular ages: there exists large heterogeneity of employment rates among OECD countries for the youngest and the oldest workers ${ }^{1}$, whereas the employment rates for workers between 30 and 50 years old are very low dispersed (see also OECD [2006]).

In this paper, we aim at showing that the canonical MP model augmented by life cycle features naturally delivers outcomes which are qualitatively in

\footnotetext{
${ }^{1}$ Note that we consider employment rates for people aged of less than 60 years in order to not capture differences in labor participation due to different normal retirement ages.
} 
Figure 1: Employment rates by age groups

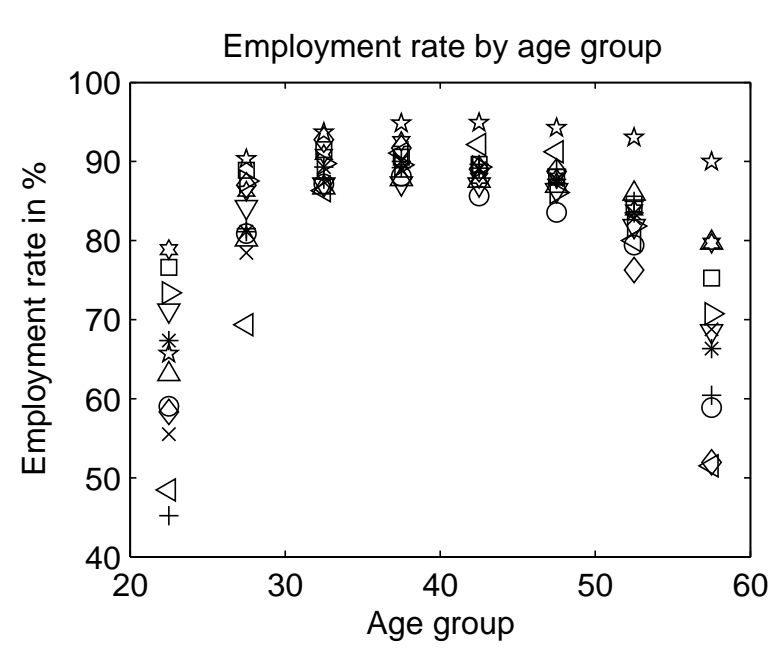

\begin{tabular}{|cl|}
\hline$\diamond$ & Bel \\
$\nabla$ & Can \\
$*$ & Ger \\
$\downarrow$ & Den \\
$\times$ & Spa \\
0 & Fin \\
+ & Fra \\
$\triangleright$ & UK \\
$\triangleleft$ & Ita \\
$\star$ & Jap \\
$\triangle$ & Swe \\
$\square$ & US \\
\hline
\end{tabular}

Source: OECD data (2000) for men. Age groups: 25-29, 30-34, 35-39, 40-44, 45-49, 50-54, 55-59.

accordance with these stylized facts, even if other factors ${ }^{2}$ are necessary to quantitatively explain all of them. Moreover, from a normative standpoint, we think that it is important to propose a theoretical framework able to give some insights on the optimality of age-designed policies. A lot of countries have implemented anti-age discrimination policy and some have experimented with job protection, unemployment benefits or employment subsidies differentiated by age ${ }^{3}$. What are their impact? Are there any rationales under these policies? If any, what would be the age profile of these policies? Our paper is a first contribution in the equilibrium unemployment framework to these questions.

We propose an equilibrium unemployment model as standard as possible in the line of Mortensen and Pissarides [1994] (MP hereafter). The existence of search frictions imply that there is a costly delay in the process of filling vacancies, and endogenous job destructions closely interact with job creations. Wages are determined according to a standard Nash bargaining ${ }^{4}$.

\footnotetext{
${ }^{2}$ One may think of the depreciation of human capital and the existence of pre-retirement systems at the end of working life, whereas the employment of the youth may depend a lot on the efficiency of the educational institutions and the hiring process.

${ }^{3}$ In Belgium, Finland, France Japan or Korea, it is more costly for firms to lay off older workers because of longer notice periods or higher severance pay. In Belgium or France, there exists more generous unemployment benefits at the end of the working life. In the UK or France, hirings of workers of more than 50 are subsidized.

${ }^{4}$ This approach has been recently criticized by Shimer [2005] and Hall [2005] as it underestimates the fluctuations of unemployment and vacancy. Taking into account real
} 
Contrary to the large literature following MP, we consider a life cycle setting characterized by a deterministic age at which workers exit the labor market. There is no more heterogeneity than the distance to retirement. We consider that this is a natural starting point to which other potential sources of heterogeneity across workers of different ages could be added ${ }^{5}$. We also consider in our benchmark economy that firms cannot ex-ante age-direct their search, that is vacancies cannot be targeted on a specific age group as the result of the legislation prohibiting age-discrimination ${ }^{6}$. Consistently, unemployed workers are randomly matched with available job vacancies irrespective of their age.

The first contribution of this paper is to reveal the direct influence of impending retirement on both job creations and destructions. We show that extending MP's framework to account for a deterministic exit date from the labor market naturally deliver a hump-shaped age-dynamics of employment. On the one hand, because the horizon of older workers is shorter, we show that firms invest less in labor-hoarding activities at the end of the life cycle. This implies that the firing (hiring) rate increases (decreases) with the age of the worker, so that the employment rate is falling at the end of the lifecycle. We argue that differences in retirement ages can account for observed differences in employment rates of older workers: more or less longer horizon of the worker on the labor market appears as a key variable to understand either smoother or sharper decrease in the employment rate from 50 years old on. On the other hand, since new entrants are unemployed, low firing rates at the beginning of the working life cycle make the employment rate increasing with age until a threshold age.

If the low employment rate of older workers can be explained by the short horizon created by the coming retirement, the next issue is then to examine the social optimality of such outcomes. Before engineering any policy devices to circumvent firms to discriminate against older workers, it is necessary to study the social optimality of such behaviors. In the context

wage rigidities as suggested by Shimer [2005] and Hall [2005] would exacerbate the life cycle impact on job flows as emphasized in section 1.

${ }^{5}$ For instance, one could think that older workers have much more job-specific skills and suffer more from separations. The amount of idiosyncratic uncertainty could be weaker for older workers. The bargaining power of younger and older workers is not necessary the same...

${ }^{6}$ This legislation in the US dates back to the 60's (Age Discrimination in Employment Act in 1967, and subsequent amendments). In 2000, the European Union Council Directive also requires all $15 \mathrm{EU}$ countries to introduce legislation prohibiting direct and indirect discrimination at work on the grounds of age. 
of matching frictions and wage bargaining, it is now well-established that the decentralized equilibrium is in general not optimal, except when the Hosios condition holds. ${ }^{7}$ In the life-cycle equilibrium, as firms are engaged in a non age-directed search, the age distribution of the unemployed workers determines the return of vacancies. Older worker job destructions exert a negative externality on the employment of the younger unemployed workers which is not internalized by firms in the decentralized equilibrium. This is why the Hosios condition is not enough to restore the social optimality of the life-cycle equilibrium: there are too much (not enough) older (younger) worker job destructions even though the optimal profile of job destructions is increasing with age as in the equilibrium outcome.

We then define the policies which could restore the efficiency of the decentralized equilibrium. We expect that the intergenerational externalities may be corrected by policies designed by age. More specifically, older worker job destructions must be reduced in order to limit the number of older unemployed workers likely to be contacted by firms. We show that the optimal design of employment subsidies is increasing with age: older worker jobs are the more subsidized whereas younger worker jobs are even taxed. Optimal firing and hiring policies could also be implemented, but in a more complex way. Indeed, the sensitivity of firm's firing policy with respect to employment protection is age-dependent. Namely, firing taxes are more efficient in the last stages of the life cycle when firms have strong incentives to wait for older worker retirement as a way of escaping from firing taxes. More precisely, at the end of the working cycle, introducing a firing tax increases the present firing cost without any future consequences on the job value as the worker will be retired in the next period. On the opposite, for a younger worker, the firing decision depends not only on the current tax but also on the expected one. We show that, everything being equal, this would require the age-dynamics of the firing tax to be decreasing. Combining this effect with the intergenerational externality leads to a hump-shaped feature for the optimal age-dynamics of the firing taxes, hence of hiring subsidies.

Lastly, in order to assess the scope of these results, we test the robustness of our model's implications with respect to the assumption of non-age directed search and constant search effort for unemployed workers. First, we show that even though age-directed recruiting policies was possible, the equilibrium would feature only non-directed recruitment policies. This result

\footnotetext{
${ }^{7}$ This condition states that the elasticity of the matching friction with respect to vacancies should be equal to worker's bargaining power (Hosios [1990]). This efficiency result could also be obtained in a competitive search equilibrium (Moen [1997]).
} 
is tightly related with the assumption that there is no age-dependent ability requirement associated with a vacant position. This actually implies that all unemployed workers, whatever their age, are eager to apply to age-directed vacant positions, so that in equilibrium only non-directed recruitment policies exist. Secondly, as unemployed search effort corresponds to an investment, we show that it adds another force to explain why older worker employment may be lower due to a shorter horizon. Unemployed older workers exhibit a lower search effort than younger workers. Interestingly, this profile is also present in the social optimum. Furthermore, the social return of older worker search is not only lower due to the shorter horizon, as it is perceived by workers, but it also negatively impacts the return of firm vacancies. This is why the profile of unemployment search subsidies should be decreasing with age. The older worker search is less worthy to be encouraged as it exerts a particularly negative externality on the younger unemployed workers by lowering the job vacancies in the economy.

The remaining of the paper is organized as follows. A first section describes the model and discusses equilibrium properties as regard with some empirical facts. The second section turns to efficiency and labor policy issues. A third section is devoted to the robustness analysis. A last section concludes the paper.

\section{Equilibrium Life Cycle Dynamics of Job Cre- ations and Job Destructions}

Let us consider an economy à la Mortensen - Pissarides [1994]. Labor market frictions imply that there is a costly delay in the process of filling vacancies, and endogenous job destructions closely interact with job creations. Contrary to the large literature following MP, we consider a life cycle setting characterized by a deterministic age at which workers exit the labor market.

\subsection{Model Environment}

We consider a discrete time model and assume that at each period the older worker generation retiring from the labor market is replaced by a younger worker generation of the same size (normalized to unity) so that there is no labor force growth in the economy. We denote $i$ the worker's age and $T$ the exogenous age at which workers exit the labor market: they are both perfectly known by employers. There is no other heterogeneity across workers. The economy is at steady-state, and we do not allow for any aggregate uncertainty. 
We assume that each worker of the new generation enters the labor market as unemployed.

\subsubsection{Shocks}

Firms are small and each has one job. The destruction flows derive from idiosyncratic productivity shocks that hit the jobs at random. Once a shock arrives, the firm has no choice but either to continue production or to destroy the job. Then, for age $i \in(2, T-1)$, employed workers are faced with layoffs when their job becomes unprofitable. At the beginning of each age ${ }^{8}$, a job productivity $\epsilon$ is drawn in the general distribution $G(\epsilon)$ with $\epsilon \in[0, \bar{\epsilon}]$. The firms decide to close down any jobs whose productivity is below an (endogenous) productivity threshold (productivity reservation) denoted $R_{i}$. Job creation takes place when a firm and a worker meet. The flow of newly created jobs result from a matching function the inputs of which are vacancies and unemployed workers. This flow also depends on productivity thresholds $R_{i}$ because it is assumed that productivity values $\epsilon$ are known after firm and worker met.

\subsubsection{Workers flows with non age-directed search}

We assume that firms cannot ex-ante age-direct their search and that the matching function embodies all unemployed workers. Let $u$ be the number of unemployment workers, $v$ the vacancies, and assume at this stage that worker search effort is exogenous. There is a matching function that gives the number of hirings as a function of the number of vacancies and the number of unemployed workers, $M(v, u)$, where $M$ is increasing and concave in both its arguments, and with constant returns-to-scale. Let $\theta=v / u$ denote the tightness of the labor market. It is then straightforward to define the probability for unemployed workers of age $i$ to be employed at age $i+1$, as $j c_{i} \equiv p(\theta)\left[1-G\left(R_{i+1}\right)\right]$ with $p(\theta)=\frac{M(u, v)}{u}$. Similarly, we define the job destruction rate for an employed worker of age $i$ as $j d_{i}=G\left(R_{i}\right)$.

At the beginning of their age $i$, the realization of the productivity level on each job is revealed. Workers hired when they were $i-1$ years old (at the end of the period) are now productive. Workers whose productivity is below the reservation productivity $R_{i}$ are either laid off or not hired (for those previously unemployed). For any age $i$, the flow from employment to unemployment is then equal to $G\left(R_{i}\right)\left(1-u_{i-1}\right)$. The other workers who

\footnotetext{
${ }^{8}$ This assumption is done to allow for analytical results. Persistency of shocks is leaved for a quantitative empirical investigation of the model performance.
} 
remain employed $\left(1-G\left(R_{i}\right)\right)\left(1-u_{i-1}\right)$ can renegotiate their wage. The age-dynamics of unemployment is then given by:

$$
u_{i+1}=u_{i}\left[1-p(\theta)\left(1-G\left(R_{i+1}\right)\right)\right]+G\left(R_{i+1}\right)\left(1-u_{i}\right) \quad \forall i \in(1, T-1)
$$

for a given initial condition $u_{1}=1$. The overall level of unemployment is $u=\sum_{i=1}^{T-1} u_{i}$, so that the average unemployment rate is $u /[T-1]$.

\subsection{Hiring and Firing Decisions}

Any firm is free to open a job vacancy and engage in hiring. $c$ denotes the flow cost of recruiting a worker and $\beta \in[0,1]$ the discount factor. Let $V$ be the expected value of a vacant position and $J_{i}(\epsilon)$ the value of a filled job with productivity $\epsilon$ :

$V=-c+\beta q(\theta) \sum_{i=1}^{T-1}\left[\frac{u_{i}}{u}\left(\int_{R_{i+1}}^{\bar{\epsilon}} J_{i+1}(x) d G(x)+G\left(R_{i+1}\right) V\right)\right]+\beta(1-q(\theta)) V$

Vacancies are determined according to the expected value of a contact with an unemployed worker. This expected value depends on the age distribution of the unemployed workers. Heterogeneity across ages in filled job values and in productivity thresholds imply the existence of intergenerational externalities in the search process. The probability of contact not only depends on the overall number of unemployed workers but also on the age distribution of this population. Typically, the more older unemployed workers are, the less is the expected return of a vacancy. The zero-profit condition $V=0$ allows us to determine the labor market tightness from the following condition:

$$
\frac{c}{q(\theta)}=\beta \sum_{i=1}^{T-1}\left(\frac{u_{i}}{u} \int_{R_{i+1}}^{\bar{\epsilon}} J_{i+1}(x) d G(x)\right)
$$

For a bargained wage $w_{i}(\epsilon)$, the expected value $J_{i}(\epsilon)$ of a filled job by a worker of age $i$ is defined by:

$$
J_{i}(\epsilon)=\epsilon-w_{i}(\epsilon)+\beta \int_{R_{i+1}}^{\bar{\epsilon}} J_{i+1}(x) d G(x)+\beta G\left(R_{i+1}\right) V \quad \forall i \in[1, T-1]
$$

It is worth emphasizing that the deterministic exit at age $T$ leads to an exogenous job destruction, whatever the productivity realization: $J_{T}(\epsilon)=0 \forall \epsilon$. 
Taking into account of the free entry $V=0$, the (endogenous) job destruction rule $J_{i}(\epsilon)<0$ leads to a reservation productivity $R_{i}$ defined by $J_{i}\left(R_{i}\right)=0 \quad \forall i \in[2, T-1]$ :

$$
R_{i}=w_{i}\left(R_{i}\right)-\beta \int_{R_{i+1}}^{\bar{\epsilon}} J_{i+1}(x) d G(x) \quad \forall i \in[2, T-1]
$$

The higher the wage, the higher the reservation productivity, and hence the higher the job destruction flows. On the other hand, the higher the option value of filled jobs (expected gains in the future), the weaker the job destructions. Because the job value vanishes at the end of the working life, labor hoarding of older workers is less profitable. It is again worth determining the terminal age condition: $R_{T-1}=w_{T-1}\left(R_{T-1}\right)$.

Property 1. For an exogenous and constant wage $w$, the reservation productivity is solving:

$$
R_{i}=w-\beta \int_{R_{i+1}}^{\bar{\epsilon}}[1-G(x)] d x
$$

with terminal conditions $R_{T-1}=w$, which implies $R_{i+1} \geq R_{i} \forall i$.

Proof. Assume $w_{i}(\epsilon)=w \quad \forall i, \epsilon$, then $J_{i}^{\prime}(\epsilon)=1$, so that $J_{i}\left(R_{i}\right)=0$ entails $J_{i}(\epsilon)=\epsilon-R_{i}$. Use (4), notice that integrating by parts $\int_{R_{i+1}}^{\bar{\epsilon}} J_{i+1}(x) d G(x)=$ $\int_{R_{i+1}}^{\bar{\epsilon}} J_{i+1}^{\prime}(x)[1-G(x)] d x=\int_{R_{i+1}}^{\bar{\epsilon}}[1-G(x)] d x$, we find $R_{i}$. Let reason backward from $i=T-1$ to $i=2$, remaining of the proof is straightforward.

Because the horizon of older workers is shorter, firms invest less in laborhoarding activities at the end of the life cycle. older workers are more vulnerable to idiosyncratic shocks, that is $R_{i+1} \geq R_{i}$ for a given $w$.

\subsection{The Wage Bargaining}

The rent associated with a job is divided between the employer and the worker according to a wage rule. Following the most common specification, wages are determined by the Nash solution to a bargaining problem ${ }^{9}$.

\footnotetext{
${ }^{9}$ Recently, this wage setting rule has been somewhat disputed (See e.g. Shimer [2005] and Hall [2005]). We leave for future research the exploration of alternative wage rules.
} 
Values of employed (on a job of productivity $\epsilon$ ) and unemployed workers of any age $i, \forall i<T$, are respectively given by:

$$
\begin{aligned}
\mathcal{W}_{i}(\epsilon)= & w_{i}(\epsilon)+\beta\left[\int_{R_{i+1}}^{\bar{\epsilon}} \mathcal{W}_{i+1}(x) d G(x)+G\left(R_{i+1}\right) \mathcal{U}_{i+1}\right] \\
\mathcal{U}_{i}= & b+\beta\left[p(\theta)\left(\int_{R_{i+1}}^{\bar{\epsilon}} \mathcal{W}_{i+1}(x) d G(x)+G\left(R_{i+1}\right) \mathcal{U}_{i+1}\right)\right. \\
& \left.+(1-p(\theta)) \mathcal{U}_{i+1}\right]
\end{aligned}
$$

with $b \geq 0$ denoting the opportunity cost of employment. ${ }^{10}$

For a given bargaining power of the workers, considered as constant across ages, the global surplus generated by a job, $S_{i} \equiv J_{i}(\epsilon)+W_{i}(\epsilon)-U_{i}$, is divided according to the following sharing rule which is the solution of the conventional Nash bargaining problem:

$$
\mathcal{W}_{i}(\epsilon)-\mathcal{U}_{i}=\gamma\left[J_{i}(\epsilon)+\mathcal{W}_{i}(\epsilon)-\mathcal{U}_{i}\right]
$$

As in MP, a crucial implication of this rule is that the job destruction is optimal not only from the firm's point of view but also from that of the worker. $J_{i}\left(R_{i}\right)=0$ indeed entails $\mathcal{W}_{i}\left(R_{i}\right)=\mathcal{U}_{i}$. Accordingly, the equilibrium wage rule solves (see appendix B.1 for details on derivation):

$$
w_{i}(\epsilon)=\gamma \epsilon+(1-\gamma)\left[\mathcal{U}_{i}-\beta \mathcal{U}_{i+1}\right]
$$

The wage is a weighted average of productivity and the reservation wage of workers. As in Pissarides [2000], and in order to state how turn-over costs interact with the wage bargaining process, a more appealing version of this wage equation may be derived by using equilibrium conditions (again see appendix B.1):

$$
w_{i}(\epsilon)=\gamma\left[\epsilon+c \theta \tau_{i}\right]+(1-\gamma) b
$$

where $\tau_{i}$ is defined as follow

$$
\tau_{i} \equiv \frac{\int_{R_{i+1}}^{\bar{\epsilon}} J_{i+1}(x) d G(x)}{\sum_{i=1}^{T-1}\left(\frac{u_{i}}{u} \int_{R_{i+1}}^{\bar{\epsilon}} J_{i+1}(x) d G(x)\right)}=\frac{\int_{R_{i+1}}^{\bar{\epsilon}}[1-G(x)] d x}{\sum_{i=1}^{T-1}\left(\frac{u_{i}}{u} \int_{R_{i+1}}^{\bar{\epsilon}}[1-G(x)] d x\right)}
$$

As in Pissarides, the way that market tightness enters the wage equation is through the bargaining strength each party has: a higher $\theta \equiv \frac{1 / q(\theta)}{1 / p(\theta)}$ indicates

\footnotetext{
${ }^{10}$ We assume that $\mathcal{W}_{T}=\mathcal{U}_{T}$ so that the social security provisions do not affect the wage bargaining and the labor market equilibrium.
} 
that expected unemployment duration $(1 / p(\theta))$ is relatively shorter than expected duration of a job vacancy $(1 / q(\theta))$; worker's bargaining strength is relatively higher and this leads to a higher wage rate. It is worth to emphasize that the way market tightness enters the wage equation in our model depends on the worker age through the variable $\tau_{i}$. This variable gives the value of a worker hired at age $i$ relative to the expected value of a job according to the age distribution of unemployed workers ${ }^{11} \cdot \tau_{i}$ decreases with age. This means that drawing a young worker is worthier than an old one for the firm; its job value is greater than the average job value. A young worker has then to be rewarded for more than the saving of the average search costs $(c \theta)$. This implies that the bargaining strength of a young worker is greater than that of an old worker, and, consequently, for a given productivity level $\epsilon$, that the wage is lower for a worker of age $i+1$ than for a worker of age $i$, $w_{i+1}(\epsilon) \leq w_{i}(\epsilon)$. Ultimately, we have $w_{T-1}(\epsilon)=\gamma \epsilon+(1-\gamma) b$.

This individual age-dynamics feature of wages is however likely to be overcome by the fact that the average productivity of jobs is increasing with ages, because (in equilibrium) firms are more reluctant to keep older workers. The next section will precisely deal with this equilibrium composition effect. ${ }^{12}$

Accordingly, combining the equation (4) with this wage equation, we may restate in a life cycle context the condition showing that a job is destroyed when the expected profit from the marginal job (current product plus option value from expected productivity shocks) fails to cover the worker's reservation wage, that is:

$$
\begin{aligned}
R_{i}+\int_{R_{i+1}}^{\bar{\epsilon}}[1-G(x)] d x & =b+p(\theta) \int_{R_{i+1}}^{\bar{\epsilon}}\left(\mathcal{W}_{i+1}(x)-\mathcal{U}_{i+1}\right) d G(x) \\
& =b+\frac{\gamma}{1-\gamma} c \theta \tau_{i}
\end{aligned}
$$

from (4), (7) and (2). The reservation wage is the sum of the unemployment benefits and the net return of the search activity. This return for the young workers is obviously higher than the average return, as $\tau_{i}>1$.

\footnotetext{
${ }^{11}$ So that we typically have $\tau_{1}>1$ for the youngest workers and $\tau_{T-1}<1$ for the oldest ones, or more generally $\tau_{i+1} \leq \tau_{i}$.

${ }^{12}$ From the individual perspective, one could also allow the model to account for exogenous human capital accumulation. We will also address this concern in the next section when dealing with the equilibrium age-profile of wages.
} 


\subsection{Life-Cycle Labor Market Equilibrium}

The primary objective of this section is to examine the equilibrium age dynamics of labor market flows and employment.

\subsubsection{Equilibrium age-dynamics of job creation and job destruc- tion}

Proposition 1. A labor market equilibrium with wage bargaining exists and it is characterized by:

$$
\begin{aligned}
\frac{c}{q(\theta)} & =\beta(1-\gamma) \sum_{i=1}^{T-1}\left(\frac{u_{i}}{u} \int_{R_{i+1}}^{\bar{\epsilon}}[1-G(x)] d x\right) \\
R_{i} & =w_{i}\left(R_{i}\right)-\beta(1-\gamma) \int_{R_{i+1}}^{\bar{\epsilon}}[1-G(x)] d x \\
w_{i}(\epsilon) & =\gamma\left[\epsilon+\beta(1-\gamma) p(\theta) \int_{R_{i+1}}^{\bar{\epsilon}}[1-G(x)] d x\right]+(1-\gamma) b \\
u_{i+1} & =u_{i}\left[1-p(\theta)\left(1-G\left(R_{i+1}\right)\right)\right]+G\left(R_{i+1}\right)\left(1-u_{i}\right)
\end{aligned}
$$

with terminal condition $R_{T-1}=b$ and a given initial condition $u_{1}$.

Proof. Let notice that (by integrating by parts) $\int_{R_{i+1}}^{\bar{\epsilon}} J_{i+1}(x) d G(x)=(1-$ r) $\int_{R_{i+1}}^{\bar{\epsilon}}[1-G(x)] d x$, the proof is then straightforward by combining (1), (2), (4), (8).

By definition of $j d_{i}=G\left(R_{i}\right)$ and $j c_{i}=p(\theta)\left[1-G\left(R_{i}\right)\right]$, the productivity threshold $R_{i}$ is the only variable that determines the shape of the age-dynamics of labor market flows.

Property 2. The age-dynamics of job creations and job destructions are governed by the sequence $\left\{R_{i}\right\}_{i=2}^{T-1}$ which solves:

$$
R_{i}=b-\beta[1-\gamma p(\theta)] \int_{R_{i+1}}^{\bar{\epsilon}}[1-G(x)] d x
$$

with terminal conditions $R_{T-1}=b$, so that the equilibrium is characterized by $R_{i+1} \geq R_{i}, j d_{i+1} \geq j d_{i}$ and $j c_{i+1} \leq j c_{i} \quad \forall i \in[2, T-1]$

Proof. Straightforward from proposition 1, and by solving backward the agedynamics of $R_{i}$ starting with the terminal condition $R_{T-1}=b$. 
Interestingly, this property states that, despite an individual age-declining profile of wages, the fall in labor hoarding with age is important enough to lead job creation (destruction) to decrease (increase) with age. Older workers are more vulnerable to idiosyncratic shocks. A shortened horizon relative to younger workers make them more exposed to firings. Otherwise stated, this reflects that labor-hoarding decreases with worker's age. In turn, it creates a downward pressure on the hirings of older workers. As only the more productive of older workers remain at work, it may be noted that the average wage can increase with age due to a composition effect.

Figure 2: Age-dynamics of the employment rate: an illustration

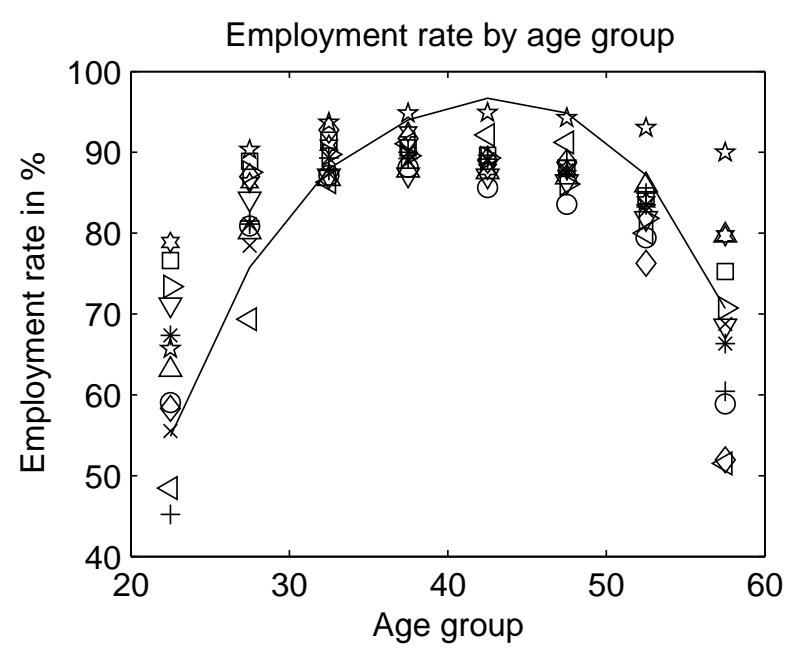

\begin{tabular}{|cl|}
\hline$\diamond$ & Bel \\
$\nabla$ & Can \\
$*$ & Ger \\
$\downarrow$ & Den \\
$\times$ & Spa \\
$\bigcirc$ & Fin \\
+ & Fra \\
$\triangleright$ & UK \\
$\triangleleft$ & Ita \\
$\downarrow$ & Jap \\
$\triangle$ & Swe \\
$\square$ & US \\
& model \\
\hline
\end{tabular}

Annual calibration: $i=1$ refers to 16 years old workers with $u_{1}=1 . G(\epsilon)=\epsilon, \forall \epsilon \in[0,1]$, $p(\theta)=\Gamma \theta^{\psi}$ with an intermediate value $T=63$, and $\beta=.96, b=.43, \psi=\gamma=.6$ from conventional external informations. $\Gamma=1.15$ and $c=.78$ consistent with $30-40$ years old average employment rate of $90 \%$, and $1 \%$ ratio of recruiting costs to average output.

\subsubsection{The age-dynamics of the employment rate}

The age profile of hirings and firings has been recursively determined from terminal conditions. On the other hand, the age profile of unemployment $u_{i}$ (or employment $n_{i}=1-u_{i}$ ) depends on the arbitrary initial condition $u_{1}$. This explains why it is ambiguous:

$$
u_{i} \gtrless \frac{G\left(R_{i+1}\right)}{[1-p(\theta)] G\left(R_{i+1}\right)+p(\theta)} \Rightarrow n_{i+1} \gtrless n_{i} \quad \forall i
$$

Property 3. For $u_{1}=1$, there exists a threshold age $\tilde{T}$ so that $n_{i} \geq$ $n_{i-1} \quad \forall i \leq \tilde{T}$ and $n_{i} \leq n_{i-1} \quad \forall i \geq \tilde{T}$. 
Proof. See Appendix C.1.

In the case where all the new entrants are unemployed, high vacancy rates and low firing rates at the beginning of the working life cycle make the employment rate increasing with age until the age $\tilde{T}$. Until this threshold age, this increase in employment rate is simply the result of a queue phenomenon. From $\tilde{T}$ on, the employment rate evolution by age mimics the age profile of firings and hirings. The overall age-dynamics of employment is thus humpshaped, as found in OECD data (see Figure 1). The figure 2 put further emphasis on this point by providing an illustrative simulation of the model for a standard calibration. It must be emphasized that the model is able to generate large variations of employment rates over the life cycle. The employment rate increases slowly and reaches its maximum around 40 years old as in most OECD countries. This illustrates the queue phenomenon in the model which mainly depends on the hiring process. After these ages, the coming retirement age reverses the profile of the employment rate as the result of the increase of the firings at the end of the working life. One again, this pattern seems consistent with the data and reinsures us that this model could be also well-suited for quantitative analysis.

\subsubsection{The Age Profile of Wages}

Since the seminal empirical work of Mincer [1962], it is well-known that the wage increases with age and declines at the end of the life cycle. This stylized fact can be explained in our model simply by including general human capital accumulation so that: $h_{i+1}=(1+\mu) h_{i}$ where the productivity of the job is now given by $h_{i} \epsilon$ which counteracts the negative impact of shorter horizon on wages, according to the value of the growth rate $\mu \geq 0$. Assuming that $b_{i} \equiv b h_{i}$, it is straightforward to see that the shape of job creations and job destructions is not altered by this assumption, since in such a case we would have:

$$
R_{i}=b-\beta(1+\mu)[1-\gamma p(\theta)] \int_{R_{i+1}}^{\bar{\epsilon}}[1-G(x)] d x
$$

so that $R_{i+1} \geq R_{i} \forall i$. However, it is obvious that the level of job creations and job destructions depends on the growth rate $\mu$.

Property 4. The lowest wage paid to employed workers is strictly increasing with age, that is $w_{i+1}\left(R_{i+1}\right)>w_{i}\left(R_{i}\right), \forall i$.

Proof. See Appendix C.2.

The property 4 emphasizes that there exists a composition effect on wages: at the end of the life cycle, firms hoard their workers less (the reservation 
productivity increases with the age of the worker, $R_{i+1} \geq R_{i}$ ), so that only the more productive remain at work. This might lead the average wage to increase with age even in the absence of human capital accumulation.

\subsubsection{Distance from retirement instead of age}

An important dimension of the model is the retirement age. Only the distance between the current age and the retirement age matters according to a horizon effect. On the contrary, the biological age does not matter in itself.

Property 5. For two retirement ages, $T$ and $T+N$, we have $R_{T-1-i}=$ $R_{T+N-1-i}$, so that $j c_{T-1-i}=j c_{T+N-1-i}$, and $j d_{T-1-i}=j d_{T+N-1-i} \forall i$.

Proof. Property 2 emphasizes that for all $T$ we have the same terminal condition: for two retirement ages, $T$ and $T+N, R_{T-1}=R_{T+N-1}=b$. Then, from backward induction, it comes that $R_{T-1-i}=R_{T+N-1-i} \forall i$.

Figure 3: Employment rates from age 30 to 64 for OECD Countries

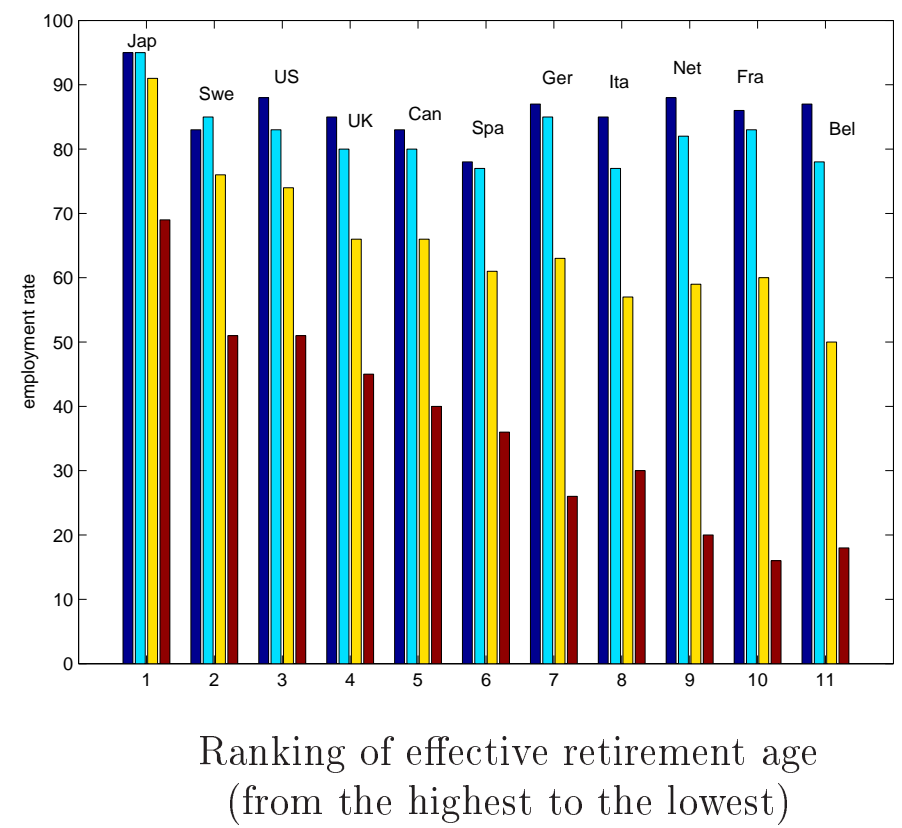

Source: OECD data for 1995 (authors' calculation). In each country, each bar refers to employment rates of the age groups : 30 - 49 (first bar on the left), 50 $54,55-59$ and 60 - 64 (last bar on the right) 
Figure 4: The impact of retirement age (RA) on employment: a quantitative illustration
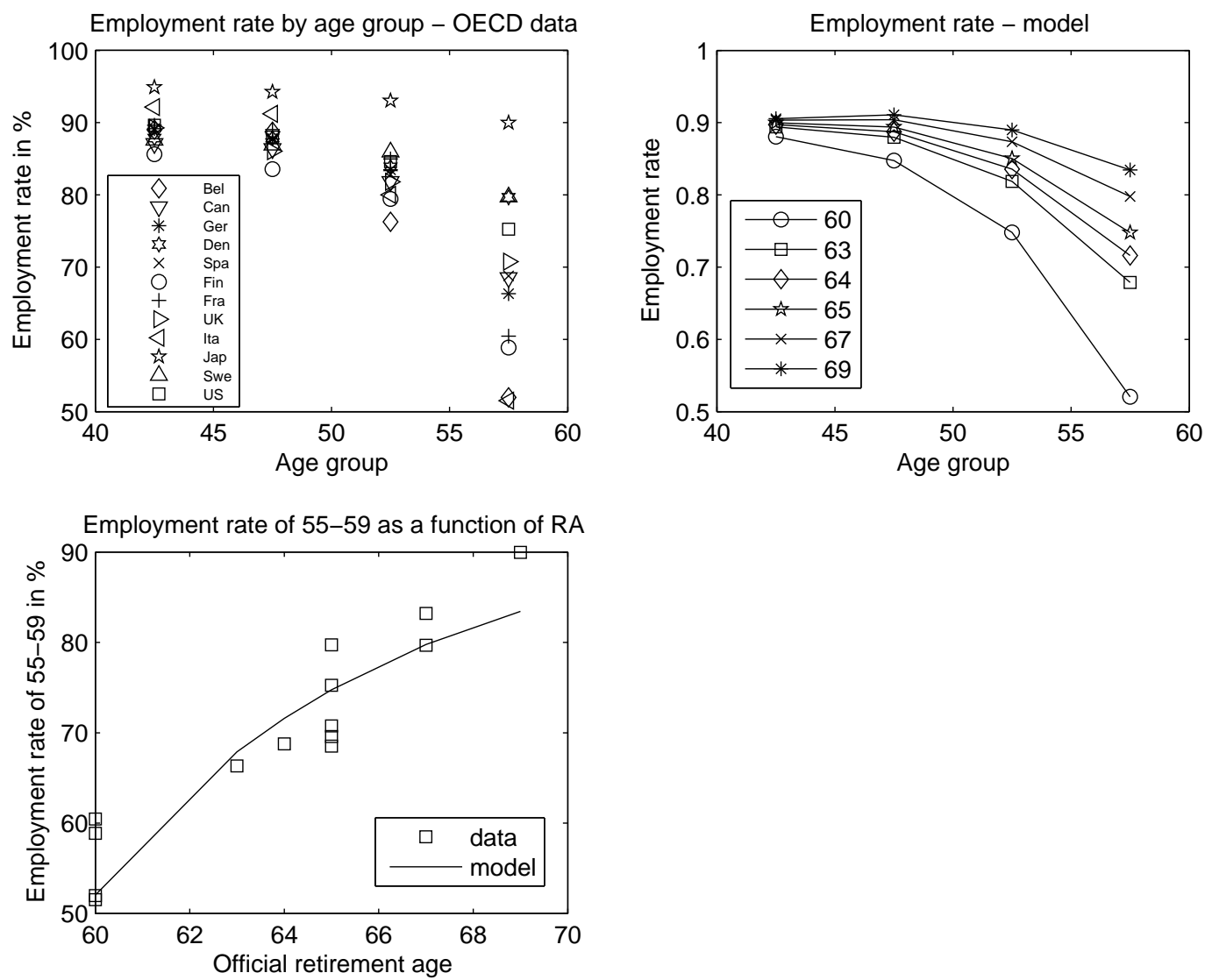

Annual calibration: $i=1$ refers to 16 years old workers with $u_{1}=1$. $G(\epsilon)=\epsilon, \forall \epsilon \in[0,1]$, $p(\theta)=\Gamma \theta^{\psi}$ with $\beta=.96, b=.43, \psi=\gamma=.6, \Gamma=1.15$ and $c=.78$. 
This may explain why countries experience a drop in their employment rate before the normal retirement age. Figure 3 shows that the fall in the employment rate of older worker is steeper when the retirement age gets closer, whatever the country considered. Two country groups emerged very clearly in the mid-nineties: those with high employment rates for workers aged 55-59 (Canada, Great Britain, Japan, the United States and Sweden) and those which already experienced a huge decrease in employment rates at these ages, around 25 points with respect to the 50-54 age group (Belgium, France, Italy and the Netherlands). As documented by Gruber and Wise [1999], the second group of countries is characterized by an effective retirement age of 60 (versus 65 in the first group). There is no reason to believe that these countries are more sensitive to the ongoing technological progress; they just display a lower retirement age.

Face to this huge decline in the employment rate just before the retirement rate, is our streamlined model able to generate quantitatively such outcomes for a standard calibration? It is not say that the horizon effect is enough to explain this decline alone. We aim to show that this effect has strong predictive power, and is not only a theoretical curiosity. The numerical experiment reproduced in Figure 4 put emphasis on this point. In panel A, OECD data show the decreasing shape of the employment rate by age for 12 countries. These 12 countries are characterized by 6 official retirement ages (RA): 60, 63, 64, 65, 67 and 69. By simulating the model for these 6 retirement ages, panel $\mathrm{B}$ gives an illustration of the property 5: starting from a similar level for the workers of age 45, the employment rates differs by a large amount 10 years later. It is less than $60 \%$ for country with a retirement age at 60 , and more $85 \%$ for a retirement age at 69 . It illustrates the large elasticity of the employment rate to the retirement age in our model. It can be noticed that the employment rate for the 50-54 age group when the retirement age is 60 is equivalent to the employment rate of the 55-60 age group in a country with a retirement age at 65 . Finally, Panel $\mathrm{C}$ shows that the magnitude of this horizon effect is in accordance with the observed heterogeneity of the employment rates in the 55-59 age group.

\section{Efficiency and Labor Market Policy in a Life- Cycle Setting}

The previous section showed that job separations (creations) occur more (less) at the end of the working life in our theoretical life-cycle setting. This result seems consistent with facts as it has been documented by OECD [2006]. 
This feature is sometimes interpreted as a discrimination against older workers, whereas our analysis shows that there exists rational arguments which push firms to differentiate their hiring and firing policies between worker ages. However, it remains to show that this behavior is not at odds with the social optimality. Traditionally, the equilibrium unemployment framework is known as generating congestion effects which take the decentralized equilibrium away from the efficient allocation. However, when the elasticity relative to vacancies in the matching function is equal to the bargaining power of firms (Hosios condition), the social optimality can be reached. Does this result still hold when life-cycle features are considered? The existence of a specific externality, namely an intergenerational externality, could lead to reconsider this result obtained in an infinite horizon. In this case, specific policies, in particular designed by age, should be implemented to restore the social optimality.

First, we show that the Hosios condition breaks down in a life cycle setting. Secondly, we propose age-designed policies to deal with the intergenerational externality in the search process.

\subsection{Intergenerational Externality and the Efficient Al- location}

We derive the optimal allocation by maximizing the steady-state output with respect to labor market tightness $\theta^{\star}$ and reservation productivity for each age, $R_{i}^{\star}$. Accordingly, the comparison of the optimal solution with the equilibrium one will be done by considering the case $\beta \rightarrow 1$.

The problem of the planner is stated as follows:

$$
\max _{\left\{R_{i}^{\star}\right\}_{i=1}^{T-1}, \theta^{\star}} \sum_{i=1}^{T-1}\left[y_{i}+b u_{i}-c \theta^{\star} \frac{\sum_{i=1}^{T-1} u_{i}}{T-1}\right]
$$

subject to the unemployment dynamics and the output equation respectively:

$$
\begin{aligned}
& u_{i+1}=G\left(R_{i+1}^{\star}\right)\left(1-u_{i}\right)+u_{i}\left(1-p\left(\theta^{\star}\right)\left[1-G\left(R_{i+1}^{\star}\right)\right]\right) \\
& y_{i+1}=u_{i} p\left(\theta^{\star}\right) \int_{R_{i+1}^{\star}}^{\bar{\epsilon}} x d G(x)+\left(1-u_{i}\right) \int_{R_{i+1}^{\star}}^{\bar{\epsilon}} x d G(x)
\end{aligned}
$$

Proposition 2. Let $\eta\left(\theta^{\star}\right)=1-\frac{\theta^{\star} p^{\prime}\left(\theta^{\star}\right)}{p\left(\theta^{\star}\right)}$, the maximum value of steady-state output is reached when $\theta^{\star}$ and $\left\{R_{i}^{\star}\right\}_{i=2}^{T-1}$ solve: 


$$
\begin{aligned}
\frac{c}{q\left(\theta^{\star}\right)}= & {\left[1-\eta\left(\theta^{\star}\right)\right] \sum_{i=1}^{T-1} \frac{u_{i}}{u}\left(\int_{R_{i+1}^{\star}}^{\bar{\epsilon}}[1-G(x)] d x\right) } \\
R_{i}^{\star}= & b-\left[1-p\left(\theta^{\star}\right)\right] \int_{R_{i+1}^{\star}}^{\bar{\epsilon}}[1-G(x)] d x \\
& -\left[1-\eta\left(\theta^{\star}\right)\right] p\left(\theta^{\star}\right) \sum_{i=1}^{T-1} \frac{u_{i}}{u}\left(\int_{R_{i+1}^{\star}}^{\bar{\epsilon}}[1-G(x)] d x\right)
\end{aligned}
$$

Proof. See appendix C.3.

Property 6. The efficient allocation is characterized by $R_{i+1}^{\star} \geq R_{i}^{\star}$, so that $j d_{i+1}^{\star} \geq j d_{i}^{\star}$ and $j c_{i+1}^{\star} \leq j c_{i}^{\star}$.

Proof. Straightforward since $0<\left[1-p\left(\theta^{\star}\right)\right]<1$ and by noticing that $[1-$ $\left.\eta\left(\theta^{\star}\right)\right] p\left(\theta^{\star}\right) \sum_{i=1}^{T-1} \frac{u_{i}}{u}\left(\int_{R_{i+1}^{\star}}^{\bar{\epsilon}}[1-G(x)] d x\right)$ is not age-dependent, that is one can examine the age-dynamics of $R_{i}$ by defining

$$
\tilde{b} \equiv b-\left[1-\eta\left(\theta^{\star}\right)\right] p\left(\theta^{\star}\right) \sum_{i=1}^{T-1} \frac{u_{i}}{u}\left(\int_{R_{i+1}^{\star}}^{\bar{\epsilon}}[1-G(x)]\right) d x .
$$

This proposition emphasizes that higher (lower) job destruction (creation) rates for older workers is not only an equilibrium outcome but also an efficient age-pattern of labor market flows. Because of their shorter horizon, older workers must be more fired and less hired. However, this does not imply that the equilibrium level of job flows is consistent with the efficient allocation.

Proposition 3. The Hosios condition, $\eta\left(\theta^{\star}\right)=\gamma$, no longer achieves efficiency in our life cycle setting.

Proof. Straightforward by comparing the expression of $R_{i}^{\star}$ in proposition 2 and $R_{i}$ in property 2 .

To see the rationale for this result, it is more convenient to restate the definition of the efficient productivity threshold as follows:

$$
R_{i}^{\star}+\int_{R_{i+1}^{\star}}^{\bar{\epsilon}}[1-G(x)] d x=b+\frac{\eta\left(\theta^{\star}\right)}{1-\eta\left(\theta^{\star}\right)} c \theta^{\star} \tau_{i}^{\star}+c \theta^{\star}\left(\tau_{i}^{\star}-1\right)
$$


where $\tau_{i}^{\star}$ is defined as previously:

$$
\tau_{i}^{\star} \equiv \frac{\int_{R_{i+1}^{\star}}^{\bar{\epsilon}}[1-G(x)] d x}{\sum_{i=1}^{T-1}\left(\frac{u_{i}^{\star}}{u^{\star}} \int_{R_{i+1}^{\star}}^{\bar{\epsilon}}[1-G(x)] d x\right)}
$$

By comparison to the equilibrium condition (10), and contrary to Pissarides [2000], it is obvious that the Hosios condition $\gamma=\eta\left(\theta^{\star}\right)$ no longer achieves efficiency in our framework because the equilibrium is no longer symmetric, that is $\tau_{i} \neq 1$. The left-hand side of (13) represents the expected profit from the marginal job occupied by a worker of age $i$. The right-hand side corresponds to the social marginal value of an unemployed worker of age $i$. It includes the leisure value $b$ and the search value specific to age $i$ unemployed workers $\left(\frac{\eta\left(\theta^{\star}\right)}{1-\eta\left(\theta^{\star}\right)} c \theta^{\star} \tau_{i}^{\star}\right)$, plus the value that this age $i$ unemployed workers provides through her impact on the average search value $\left(c \theta^{\star}\left(\tau_{i}^{\star}-1\right)\right)$. The Hosios condition $\gamma=\eta\left(\theta^{\star}\right)$ allows the private agents to internalize traditional search externalities in the decentralized equilibrium. However, because the last term $c \theta^{\star}\left(\tau_{i}^{\star}-1\right)$ in the social value of unemployment does not appear in the equilibrium condition (10), the Hosios condition no longer achieves efficiency. This last term reflects that the social value of the search activity is not symmetrical: because a young (old) worker increases (decreases) the average search value in the economy, the social value of the young (old) unemployed worker is larger (smaller) than its market value. Hence, contrary to the firms, the planner takes into account the impact of a particular unemployed worker of age $i$ on the search process. Compared to Pissarides [2000], our life-cycle framework introduces another externality, namely an intergenerational externality. The planner internalizes that firings of older (younger) worker, by increasing unemployment of this age-type of workers, reduce (increase) the average value of vacancies. On the contrary, firms neither take into account that firings of older workers reduce the average value of a job match nor that firing of younger workers increase this average value.

Overall, this suggests that the efficient rate of job destructions for older (younger) workers is lower (higher) than at equilibrium. The examination of the age-pattern of optimal labor policies will put emphasis on this result.

\subsection{The Equilibrium with Policies}

The design of age-dependent labor market policies may allow firms to internalize the intergenerational externality in their firing policy. Traditionally, the optimality can be restored either by employment subsidies/taxes or by firing and hiring subsidies/taxes. Following the same approach, we introduce 
these policies, but potentially differentiated by age. In order to specifically deal with the intergenerational externality, we assume that the Hosios condition holds hereafter.

Let us denote $a_{i}$ an employment subsidy for the worker, $F_{i}$ a firing tax which refers to the implicit costs in mandated employment protection legislation and in experience-rated unemployment insurance taxes, and $H_{i}$ a hiring subsidy. We consider a two-tier wage structure in line with Mortensen and Pissarides [1999] and Pissarides [2000].

Proposition 4. A labor market equilibrium with wage bargaining and labor market policies exists, it is characterized by:

$$
\begin{aligned}
\frac{c}{q(\theta)}= & \beta(1-\gamma) \sum_{i}\left[\frac{u_{i}}{u}\left(\int_{R_{i+1}+F_{i+1}-H_{i+1}}^{\bar{\epsilon}}\left[x-R_{i+1}+H_{i+1}-F_{i+1}\right] d G(x)\right)\right] \\
R_{i}= & b-a_{i}-F_{i}+\beta F_{i+1}-\beta \int_{R_{i+1}}^{\bar{\epsilon}}\left(x-R_{i+1}\right) d G(x) \\
& +\gamma \beta p(\theta) \int_{R_{i+1}+F_{i+1}-H_{i+1}}^{\bar{\epsilon}}\left[x-R_{i+1}+H_{i+1}-F_{i+1}\right] d G(x) \\
u_{i+1}= & u_{i}\left[1-p(\theta)\left(1-G\left(R_{i+1}\right)\right)\right]+G\left(R_{i+1}\right)\left(1-u_{i}\right)
\end{aligned}
$$

with terminal condition $R_{T-1}=b-a_{T-1}-F_{T-1}$ and a given initial condition $u_{1}$.

Proof. See Appendix A.

\subsection{The Optimal Age-Dynamics of Employment Subsi- dies}

We first determine the employment subsidy policy suitable in the life cycle framework. We thus assume $\eta\left(\theta^{\star}\right)=\gamma$ and $F_{i}=H_{i}=0, \forall i$.

Property 7. Let consider $\beta \rightarrow 1$ and $\eta\left(\theta^{\star}\right)=\gamma$, an optimal age-sequence for employment subsidies, denoted $\left\{a_{i}\right\}_{i=1}^{T-1}$ solves:

$$
a_{i}=c \theta^{\star}\left(1-\tau_{i}^{\star}\right)
$$

where $\theta^{\star}, R_{i}^{\star}$ hence $u_{i}^{\star}$ are defined by proposition 2.

Proof. Straightforward by comparing propositions 2 and 4 and recalling that $\int_{R_{i+1}^{\star}}^{\bar{\epsilon}}[1-G(x)] d x=\int_{R_{i+1}^{\star}}^{\bar{\epsilon}}\left(x-R_{i+1}\right) d G(x)$. 
Corollary 1. The optimal age-dynamics of employment subsidies is increasing with age, $a_{i+1}^{\star}>a_{i}^{\star} \forall i \in[0, T-1]$, and there exists a threshold age $\tilde{t}$ such that $a_{i} \leq 0 \quad \forall i \in[0, \tilde{t}]$ and $a_{i} \geq 0 \quad \forall i \in[\tilde{t}, T-1]$.

Proof. Straightforward since from $R_{i+1}^{\star} \geq R_{i}^{\star}$, we have $\tau_{i+1}^{\star} \leq \tau_{i}^{\star}$ and $\tau_{1}>1$, $\tau_{T-1}<1$.

As the younger (older) workers exert a positive (negative) externality on hirings of older (younger) workers, there are not enough (much) destructions of younger (older) worker jobs. This implies to subsidy more employment of older workers, and even to tax the employment of younger workers (for $i \leq \tilde{t})$.

\subsection{Revisiting the Role of Firing taxes}

Alternatively to the employment tax/subsidy, it is traditional to also consider firing taxes. This implies to also implement hiring subsidies in order to compensate for the effect of these firing taxes on hirings. Indeed another way to reduce the unemployment of older worker is to protect their employment by introducing age-increasing firing taxes together with hiring subsidies. However, this intuition will not be totally valid because of the particular strong effect of firing taxes at the end of the working life. We first investigate this point and then turn to the optimal age-profile of hiring and firing taxes.

\subsubsection{On the age-differentiated effect of firing taxes}

We argue that, in a life cycle setting, there exists a non-trivial intertemporal trade-off related to the introduction of firing taxes. To put emphasis on this result, we consider a constant tax, $F$, and compare its impact in our life cycle setting versus in a MP economy $(T \rightarrow \infty)$.

To that end, let first notice that, with $T \rightarrow \infty$, the productivity threshold and the labor market tightness would jump on stationary values that we denote $R$ and $\theta$ respectively.

Property 8. If $T \rightarrow \infty$, the labor market equilibrium with firing taxes $F$ is characterized by $\{R, \theta\}$ solving: 


$$
\begin{aligned}
\frac{c}{q(\theta)}= & \beta(1-\gamma) \int_{R+F}^{\bar{\epsilon}}(x-R-F) d G(x) \\
R= & b-(1-\beta) F-\beta p(\theta) \int_{R}^{\bar{\epsilon}}(x-R) d G(x) \\
& +\beta \gamma p(\theta)] \int_{R+F}^{\bar{\epsilon}}(x-R-F) d G(x)
\end{aligned}
$$

Proof. Straightforward from Proposition 4 by considering $R_{i}=R_{i+1}=R$.

Corollary 2. Let assume $\gamma \rightarrow 0$, the labor market equilibrium is characterized by:

$$
0 \geq \frac{d R}{d F}>\frac{d R_{2}}{d F}>\frac{d R_{i}}{d F} \ldots>\frac{d R_{T-1}}{d F} \quad \forall i \in[2, T-1]
$$

Proof. Since, on the one hand, $\frac{d R}{d F}=-(1-\beta)$ and on the other hand, $\frac{d R_{i}}{d F}=$ $-(1-\beta)+\beta\left[1-G\left(R_{i+1}\right] \frac{d R_{i+1}}{d F}\right.$ with $\frac{d R_{T-1}}{d F}=-1$, the proof is straightforward.

To get some intuitions on this result, let us consider the particular case where both $\beta \rightarrow 1$ and $\gamma \rightarrow 0$. It is straightforward to see that $\frac{d R}{d F}=0$ whereas $\frac{d R_{T-1}}{d F}=-1$ implies $\frac{d R_{i}}{d F}<0 \quad \forall i$. At the end of the working cycle, introducing a firing tax increases the present firing cost without any future consequences on the job value as the worker will be retired in the next period. On the other hand, in an infinite horizon, the present firing cost increases in the same proportion as in our life-cycle model, but the job value decreases, as the firm rationally expect the future cost of the firing tax. In some sense, retirement allows firms to escape from the firing tax, leading them to more labor hoarding for older workers. This suggests that evaluating employment protection in an infinite-lived agents context underestimates the potential positive impact on employment. The proof of this result in the general specification where $\gamma>0$ is not trivial, since the larger impact of $F$ on $R_{i}$ in our life cycle setting accounts for a lower decrease of $\theta$, hence of wages, than in an infinite-horizon framework.

Nevertheless, for some parametric specifications, we are able to state a sufficient condition on the level of $F$ whose implication is a decreasing agedynamics of $R_{i}$. 
Property 9. If $F-\int_{b-F}^{b}[1-G(x)] d x \geq \int_{b}^{\bar{\epsilon}}[1-G(x)] d x$, then $R_{T-1} \leq R_{i+1} \leq$ $R_{i} \forall i \in[2, T-1]$.

Proof. From the definition of $R_{i}$ in proposition 4 , by assuming $F_{i}=F$ and $a_{i}=H_{i}=0$, we have

$$
\begin{aligned}
R_{i}= & b-(1-\beta) F-\beta \int_{R_{i+1}}^{\bar{\epsilon}}\left(x-R_{i+1}\right) d G(x) \\
& +\gamma \beta p(\theta) \int_{R_{i+1}+F}^{\bar{\epsilon}}\left(x-R_{i+1}-F\right) d G(x)
\end{aligned}
$$

Let define $\Psi(z) \equiv \int_{z}^{\bar{\epsilon}}(x-z) d G(x)-\gamma p(\theta) \int_{z+F}^{\bar{\epsilon}}(x-z-F) d G(x)=\int_{z}^{\bar{\epsilon}}[1-G(x)) d x-$ $\gamma p(\theta) \int_{z+F}^{\bar{\epsilon}}[1-G(x)] d x$, it comes $\Psi^{\prime}(z)<0$, so that if $R_{T-2} \geq R_{T-1}$, then $R_{i} \geq R_{i+1} \quad \forall i$. Then,

$R_{T-2} \geq R_{T-1}=b-F \Longleftrightarrow F \geq \int_{b-F}^{\bar{\epsilon}}[1-G(x)] d x-\gamma p(\theta) \int_{b}^{\bar{\epsilon}}[1-G(x)] d x$

which implies that $F \geq \int_{b-F}^{\bar{\epsilon}}[1-G(x)] d x$ is a sufficient condition for $R_{T-2} \geq$ $R_{T-1}$, hence $R_{i} \geq R_{i+1}$. Remaining of the proof is straightforward.

This proposition states that the employment protection can be sizeable enough at the end of the life cycle to imply that older workers face a lower risk of job destruction than younger ones. This property has strong implications on the optimal age-dynamics of firing taxes and hiring subsidies.

\subsubsection{The optimal age-dynamics of firing taxes and hiring subsi- dies}

Let now consider $a_{i}=0 \quad \forall i$. Firing taxes together with hiring subsidies are now used to reach the first best allocation.

Property 10. Let consider $\beta \rightarrow 1$ and $\eta\left(\theta^{\star}\right)=\gamma$, an optimal age-sequence for firing taxes and hiring subsidies $\left\{F_{i}^{\star}, H_{i}^{\star}\right\}_{i=1}^{T-1}$ solves:

$$
\begin{aligned}
F_{i+1}^{\star}-F_{i}^{\star} & =c \theta^{\star}\left(1-\tau_{i}^{\star}\right) \\
H_{i}^{\star} & =F_{i}^{\star} \forall i
\end{aligned}
$$

where $F_{T-1}^{\star}=H_{T-1}=0$ and $\theta^{\star}$ and $R_{i}^{\star}$ are defined by proposition 2. 
Proof. Straightforward by comparing propositions 2 and 4 and recalling that $\int_{R_{i+1}^{\star}}^{\bar{\epsilon}}[1-G(x)] d x=\int_{R_{i+1}^{\star}}^{\bar{\epsilon}}\left(x-R_{i+1}\right) d G(x)$.

Corollary 3. The optimal age-dynamics of firing taxes and hiring subsidies is hump-shaped, first increasing and then decreasing. Let $\eta\left(\theta^{\star}\right)=\gamma, F_{i+1}^{\star}>$ $F_{i} \quad \forall i<\tilde{t}$ and $F_{i+1}^{\star} \leq F_{i} \quad \forall i \geq \tilde{t}$.

Proof. Straightforward since from $R_{i+1}^{\star} \geq R_{i}^{\star}$, we have $\tau_{i+1}^{\star} \leq \tau_{i}^{\star}$ and $\tau_{1}>1$, $\tau_{T-1}<1$.

This hump-shaped profile comes from two opposite forces:

- as previously stated, there are too much (not enough) destructions for older (younger) workers, which would require, everything else being equal, an increasing profile of firing taxes and hiring subsidies.

- there is an additional force (with respect to the case of the employment subsidy) because the firing tax specifically introduces an intertemporal trade off: the firm can avoid the tax by waiting for the worker retirement. In words, at the end of the life cycle, a lower tax is enough to reduce firings of older workers, because firms have strong incentives to wait for retirement of the worker. This suggests that although oldest workers are responsible for large negative externalities on hirings of younger workers, it is optimal to implement a lower firing tax at the end of the life cycle. ${ }^{13}$

\section{Robustness}

This section examines robustness of our results regarding two assumptions: (i) non-age directed recruiting policies and (ii) constant search effort of unemployed workers.

Firstly, we show that, even though firms could implement age-directed recruitment policies, unemployed workers' search strategy among the set of sub-markets would lead the equilibrium to be ex-ante non-directed.

Secondly, introducing endogenous unemployed search effort is found to reinforce our main results: at the equilibrium, search effort is decreasing with age and the older worker search is less worthy to be encouraged as it exerts a negative congestion effect on the younger unemployed workers.

\footnotetext{
${ }^{13}$ Another way to understand this result would consist of considering an equilibrium distortion which would be not age related, let say a constant unemployment benefit denoted $z$. In such case, the optimal shape of firing tax would be age decreasing, that is $F_{i}=$ $z+F_{i+1}$ with $F_{T-1}=z$.
} 


\subsection{Age-directed Search}

The non age-directed search hypothesis appeared to play a key role in the preceding results: it generates an intergenerational externality which was at the heart of the market equilibrium sub-optimality. Obviously, if the model environment allows to use $T-1$ matching technologies, one for each age, this specific externality would disappear.

Let consider age-directed recruitment policies, so that we define the probability of filling a vacancy as $q\left(\theta_{i}\right) \equiv \frac{M\left(v_{i}, u_{i}\right)}{v_{i}}$ for the firm. In that context, any firm is free to open a job vacancy and engage in hiring directed to worker of age $i$. Let $V_{i}$ be the expected value of a vacant job directed to a worker of age $i$ :

$V_{i}=-c+\beta\left[q\left(\theta_{i}\right) \int_{R_{i+1}^{d}}^{\bar{\epsilon}} J_{i+1}^{d}(x) d G(x)\right]+\beta\left[q\left(\theta_{i}\right) G\left(R_{i+1}^{d}\right)+\left(1-q\left(\theta_{i}\right)\right)\right] \max _{i}\left\{V_{i}\right\}$

As $J_{T}^{d}(\epsilon)=0$, no firm search for workers of age $T-1$, that is $\theta_{T-1}=0$. The zero-profit condition $V_{i}=0 \quad \forall i \in(1, T-2)$ allows us to determine the labor market tightness for each age $\theta_{i}$ from the following equation:

$$
\frac{c}{q\left(\theta_{i}\right)}=\beta \int_{R_{i+1}^{d}}^{\bar{\epsilon}} J_{i+1}^{d}(x) d G(x)
$$

This equation implies that differences in expected values of jobs according to the worker's ages have to be associated with consistent differences in expected recruitment costs. Lower expected values for older workers requires lower expected recruiting costs. However, this age-directed strategy will not be validated by unemployed workers' search among the set of sub-markets and will not exist at the equilibrium.

Proposition 5. There is no stable equilibrium allocation with age-directed search.

Proof. Because there is no age-dependent ability requirement associated with the vacancy position in our model ${ }^{14}$, an employed worker of age $i \neq j$ or $j$ gives rise to the same output $\epsilon$ into a job ex-ante age-directed toward a worker

\footnotetext{
${ }^{14}$ If in turn we would have considered that only workers of a given age can apply to age $i$-directed vacancies because of technological/organizational considerations, let say job production is $h_{i, j} \epsilon$ with $h_{i, i}=1$ and $h_{i, j}=0$ with $j \neq i$, then an age-directed search equilibrium would exist. Furthermore, since this equilibrium no longer features intergenerationnal search externalities, the Hosios condition would achieve efficiency (proof available upon request).
} 
of age $j$. The expected value of an unemployed worker of age $i$ who searches in an age $j$ segment is as follows:

$$
\begin{aligned}
\mathcal{U}_{i, j}^{d} & =b+\beta\left[p\left(\theta_{j}\right)\left(\int_{R_{i+1}^{d}}^{\bar{\epsilon}} \mathcal{W}_{i+1, j}^{d}(x) d G(x)+G\left(R_{i+1}^{d}\right) \mathcal{U}_{i+1, j}^{d}\right)+\left(1-p\left(\theta_{j}\right)\right) \mathcal{U}_{i+1, j}^{d}\right] \\
& =b+c \theta_{i} \frac{p\left(\theta_{j}\right)}{p\left(\theta_{i}\right)}+\beta \mathcal{U}_{i+1, j}^{d}
\end{aligned}
$$

where we apply the ex-post wage bargaining rule $\mathcal{W}_{i, j}^{d}-\mathcal{U}_{i, j}^{d}=\frac{\gamma}{1-\gamma} J_{i}(\epsilon)$.

It is then obvious that a worker of age $i$ has incentives to search in sub-market $j$ instead of $i$, until he expects a higher probability of contact: $\mathcal{U}_{i, j}^{d}>\mathcal{U}_{i}^{d} \Longleftrightarrow p\left(\theta_{j}\right)>p\left(\theta_{i}\right) \Longleftrightarrow \theta_{j}>\theta_{i}$. Consequently, perfect mobility of unemployed workers among sub-markets implies that $\theta_{i}=\theta_{j} \forall i, j$, and finally $\mathcal{U}_{i, j}^{d}=\mathcal{U}_{i, i}^{d} \forall i, j$. The age-directed search strategy of firms is then not validated by the strategy of unemployed workers.

The condition (13), which relies on the assumption that only $u_{i}$ unemployed of workers of age $i$ apply to $i$-type vacancy positions cannot hold in equilibrium. Instead, in each sub-market $\frac{1}{T-1} \sum_{i=1}^{T-1} u_{i}$ unemployed workers apply to the vacant positions, with the same distribution of ages as in the nondirected search equilibrium. In turn, in each sub-market $v_{j}=v /[T-1] \forall j$ where $v$ stands for the non-directed equilibrium number of vacancies, with $\theta=\frac{v /(T-1)}{\left(\sum_{i=1}^{T-1} u_{i}\right) /(T-1)}=\frac{v}{u}$ and $u$ are defined by proposition 1 .

Even though age-directed search is technologically possible, the equilibrium features ex-ante only non-directed recruiting policies.

\subsection{The Role of Endogenous Unemployed Search Effort}

We propose to extend the benchmark case (with non age-directed search) to unemployment search. We analyze both the market equilibrium outcome and its efficiency. As workers come closer to retirement age, the return to search should decrease, reinforcing the decline in older worker employment.

Let $e_{i}$ be the endogenous search effort for a worker of age $i$, the total number of hirings is now given by $M\left(v, \sum_{i} u_{i} e_{i}\right)$. Then, from the perspective of an unemployed worker the contact probability is $\frac{M\left(v, \sum_{i} u_{i} e_{i}\right)}{\sum_{i} u_{i}} \frac{e_{i}}{\tilde{e}}$ where $\tilde{e}$ is the average search effort (by definition $\tilde{e} \equiv \frac{\sum_{i} u_{i} e_{i}}{\sum_{i} u_{i}}$ ). The probability for unemployed workers of age $i$ to be employed at age $i+1$ is $e_{i} p(\theta)\left[1-G\left(R_{i+1}\right]\right.$ where $\theta \equiv v /\left[\sum_{i} u_{i} e_{i}\right]$. The endogenous search effort is derived from the following intertemporal problem: 


$$
\begin{aligned}
\mathcal{U}_{i}= & \max _{e_{i}}\left\{b-\phi\left(e_{i}\right)+\beta\left[e_{i} p(\theta) \int_{R_{i+1}}^{\bar{\epsilon}} \mathcal{W}_{i+1}(x) d G(x)\right.\right. \\
& \left.\left.+e_{i} p(\theta) G\left(R_{i+1}\right) \mathcal{U}_{i+1}+\left(1-e_{i} p(\theta)\right) \mathcal{U}_{i+1}\right]\right\}
\end{aligned}
$$

where $\phi^{\prime}>0, \phi^{\prime \prime}>0$ and $\phi(0)=0$. Accordingly, the optimal search effort solves:

$$
\begin{aligned}
\phi^{\prime}\left(e_{i}\right) & =\beta p(\theta) \int_{R_{i+1}}^{\bar{\epsilon}}\left[\mathcal{W}_{i+1}(x)-\mathcal{U}_{i+1}\right] d G(x) \\
& =\frac{\gamma}{1-\gamma} \theta \tau_{i}
\end{aligned}
$$

Search effort is decreasing with age, since the expected surplus related to employment is decreasing with $i$; ultimately, $e_{T-1}=0$.

Proposition 6. Let restate $j c_{i}=e_{i} p(\theta)\left[1-G\left(R_{i+1}\right)\right]$, the equilibrium allocation is characterized by $R_{i+1} \geq R_{i}$ and $e_{i+1} \leq e_{i}$, so that $j d_{i+1} \geq j d_{i}$ and $j c_{i+1} \leq j c_{i}$.

This result states that the search effort of workers in addition of the job destruction of firms contributes to decrease job creation flows as the retirement age is coming.

In turn, the problem of the planner can now be restated as follows:

$$
\max _{\left\{R_{i}^{\star}, v^{\star}, e_{i}^{\star}\right\}_{i=1}^{T-1}} \sum_{i=1}^{T-1}\left[y_{i}+u_{i}\left(b-\phi\left(e_{i}^{\star}\right)\right)-c \frac{v^{\star}}{T-1}\right]
$$

subject to the constraints:

$$
\begin{aligned}
& u_{i+1}=G\left(R_{i+1}^{\star}\right)\left(1-u_{i}\right)+u_{i}\left(1-\frac{e_{i}^{\star}}{\sum_{i} u_{i} e_{i}^{\star}} M\left(v, \sum_{i} u_{i} e_{i}^{\star}\right)\left[1-G\left(R_{i+1}^{\star}\right)\right]\right) \\
& y_{i+1}=u_{i} \frac{e_{i}^{\star}}{\sum_{i} u_{i} e_{i}^{\star}} M\left(v^{\star}, \sum_{i} u_{i} e_{i}^{\star}\right) \int_{R_{i+1}^{\star}}^{\bar{\epsilon}} x d G(x)+\left(1-u_{i}\right) \int_{R_{i+1}^{\star}}^{\bar{\epsilon}} x d G(x)
\end{aligned}
$$

so that the resulting optimal search effort is solving:

$$
\phi^{\prime}\left(e_{i}^{\star}\right)=\frac{\eta\left(\theta^{\star}\right)}{1-\eta\left(\theta^{\star}\right)} c \theta^{\star} \tau_{i}^{\star}-c \theta\left(1-\tau_{i}^{\star}\right) \int_{R_{i+1}^{\star}}^{\bar{\epsilon}}\left(x-R_{i+1}^{\star}\right) d G(x)
$$


Let consider $\beta \rightarrow 1$ and $\eta\left(\theta^{\star}\right)=\gamma$. It is straightforward to see that even if $\theta=\theta^{\star}, e_{i}$ differs from $e_{i}^{\star}$, and the optimal level of search effort for younger (older) workers have to be higher (lower) than at equilibrium. To understand this result, let think about the optimal age pattern of a subsidy conditional to the level of search effort, $s_{i} e_{i}$. The instantaneous utility of a unemployed worker is then $b-\phi\left(e_{i}\right)+s_{i} e_{i}$. Let also introduce for instance an employment subsidy $a_{i}$ as before, to achieve efficiency, that is $\theta=\theta^{\star}, R_{i}=R_{i}^{\star}$ and $e_{i}=e_{i}^{\star}$.

Property 11. Let consider $\beta \rightarrow 1$ and $\eta\left(\theta^{\star}\right)=\gamma$, an optimal age-sequence for employment and search effort subsidies, denoted $\left\{a_{i}^{\star}, s_{i}^{\star}\right\}_{i=1}^{T-1}$ solves:

$$
\begin{aligned}
a_{i}^{\star} & =c \theta^{\star}\left(1-\tau_{i}^{\star}\right) \\
s_{i}^{\star} & =-a_{i}^{\star}
\end{aligned}
$$

Corollary 4. The optimal age-dynamics of employment and search effort subsidies are characterized by $a_{i+1}^{\star}>a_{i}^{\star}$ and $s_{i+1}^{\star}<s_{i}^{\star} \forall i \in[0, T-1]$, and there exists a threshold age $\tilde{t}$ such that $a_{i} \leq 0, s_{i} \geq 0 \quad \forall i \in[0, \tilde{t}]$ and $a_{i} \geq 0, s_{i} \leq 0 \quad \forall i \in[\tilde{t}, T-1]$.

This suggests that is not only optimal to subsidy employment of older workers but also to tax search effort of these workers. Both these results are consistent with the idea that unemployed older workers exert a negative externality on the other unemployed workers. This result gives some theoretical arguments to the existence of pre-retirement schemes in some European countries.

\section{Conclusion}

Because the horizon of older workers is shorter, firms and workers invest less in job-search and labor-hoarding activities at the end of the life cycle: hiring (firing) rate decreases (increases) with age. As younger workers start as unemployed, the age-dynamics of employment is hump-shaped. This result shows that the normal retirement age is the key institution which governs the employment rate of older workers. Countries with a low retirement age would also suffer from a depressed employment rate for older workers relatively early in ages. This may explain why countries with a retirement age around 60 like France, Belgium has also a lower employment rate for workers aged between 55 and 59 than those with a retirement age of 65 like Sweden, the United States. 
We show that this age-profile of job creations and job destructions is an equilibrium outcome that appears particularly robust in the life-cycle framework. However, age-policies are necessary to reach the optimal social output when the labor market is not segmented by age. At equilibrium, there are indeed not enough (too much) job destructions for older (younger) workers. This feature comes from the existence of a negative effect exerted by unemployed older workers on the expected vacancy return which penalizes the other unemployed workers. This is why it is optimal to subsidy the employment of older workers. It does not however imply that increasing firing taxes during the life cycle are optimal as firing costs are very efficient for employment protection when the retirement age is coming. Concerning labor supply, we show that it could be optimal to discourage search effort of the older workers. For a given retirement age, these results give some rationales to age policies, such as pre-retirement, implemented in some European countries.

This paper assumed that workers only differ respectively to their distance from deterministic retirement. In that context, age-directed recruitment policies cannot exist in equilibrium because there are any ability or organizational age-requirement associated with jobs in the economy under study. As our study gives strong importance to the non-segmented features both at the positive and normative levels, a next issue could be to study the conditions under which age-segmented labor market could arise and their welfare implications. However, as it was already emphasized by Kaufman and Spilerman [1982], whether or not there exists such rationales for age-segmented markets is an empirical disputed issue.

Beyond its theoretical interest, we believe that the life-cycle unemployment approach is able to deliver realistic empirical predictions. We have already emphasized that some qualitative features such as the drop in the employment rate at proximity of the retirement age are very well replicated. It remains to assess the quantitative performance of this approach. It certainly implies to take into account other features of the life cycle. The first candidate is human capital, both through initial training and experience accumulated during the working life. It could be interesting to study its interplay with labor market institutions in the line of Wasmer [2004]. We think that the life cycle unemployment framework provides a very promising research agenda. 


\section{References}

[1] O. Blanchard and P. Portugal, What Hides behind an Unemployment Rate: Comparing Portuguese and U. S. Labor Markets, American Economic Review, 91 (2001), 187-207

[2] J. Gruber and D. Wise, Social security around the world, NBER Conference Report (1999).

[3] J-O. Hairault, F. Langot, and T. Sopraseuth, The interaction between retirement and job search: a global approach to older workers employment, IZA discussion paper, 1984 (2006).

[4] R. Hall, Employment fluctuations with equilibrium wage stickiness, American Economic Review, 95 (2005), 53-69.

[5] J. Heckman, Life cycle consumption and labor supply: An explanation of the relationship between income and consumption over the life cycle, American Economic Review, 64 (1974), 188-194.

[6] A.J. Hosios, On the efficiency of matching and related models of search and unemployment, Review of Economic Studies 57 (1990), 279-298.

[7] R. Hutchen, Do job opportunities decline with age, Industrial and Labor Relation Review, 42 (1988), 89-99.

[8] L. Ljungqvist and T. Sargent, The European Unemployment Experience: Uncertainty and Heterogeneity, working paper (2005).

[9] L. Ljungqvist and T. Sargent, The European Unemployment Dilemma, Journal of Political Economy, 106 (1998), 514-550.

[10] T. E. MaCurdy, An empirical model of labor supply in a life-cycle setting, Journal of Political Economy,89 (1981), 1059-1085.

[11] J. Mincer, On-the-job training: Costs, Returns, and Some Implications, Journal of Political Economy, 70 (1962), 50-79.

[12] E. Moen, Competitive search equilibrium, Journal of Political Economy, 105 (1997), 385-411.

[13] D.T. Mortensen and C. Pissarides, Job creation and job destruction in the theory of unemployment, Review of Economic Studies, 61 (1994), 397-415. 
[14] D.T. Mortensen and C. Pissarides, New developments in models of search in the labor market, Handbook of Labor Economics, North-Holland: Amsterdam (1999).

[15] OECD publishing, Live longer, work longer, Ageing and Employment Policies (2006).

[16] W. Oi, Labor as a quasi-fixed factor of production, Journal of Political Economy, 70 (1962), 538-55.

[17] C. Pissarides, Equilibrium unemployment, MIT Press (2000).

[18] E. Prescott, Why do Americans work so much more than Europeans?, Quarterly Review of the Federal Reserve Bank of Minneapolis, July (2004), 2-13.

[19] R. Rogerson, Understanding Differences in Hours Worked, Review of Economic Dynamics, 9 (2006), 365-409.

[20] J. Seater, A unified model of consumption, labor supply and job search, Journal of Economics Theory, 14 (1977), 349-372.

[21] R. Shimer, The cyclical behavior of equilibrium unemployment and vacancies, Ameriacan Economic Review, 95 (2005), 25-49.

\section{A The extended model with policy}

Let us denote $H_{i}$ a lump sum paid to the employer when a new worker of age $i$ is hired, $F_{i}$ the firing cost and $a_{i}$ the the employment subsidy for employed workers. We follow MP by considering that the wage structure that arises as a Nash bargaining solution has two tiers. The first tier wage reflects the fact that hiring subsidy is directly relevant to the decision to accept a match and that the possibility of incurring firing costs in the future affects the value the employer places on the match. In turn, the second tier wage applies when firing costs are directly relevant to a continuation decision.

Let the subscript $i=0$ index the initial wage and the value of a job under the terms of the two-tier contract, firms' value functions solve: 


$$
\begin{aligned}
V= & -c+\beta q(\theta) \sum_{i=1}^{T-1}\left[\frac{u_{i}}{u}\left(\int_{R_{i+1}^{0}}^{\bar{\epsilon}}\left[J_{i+1}^{0}(x)+H_{i+1}\right] d G(x)+G\left(R_{i+1}\right) V\right)\right] \\
& +\beta(1-q(\theta)) V \\
J_{i}^{0}(\epsilon)= & \epsilon-w_{i}^{0}(\epsilon)+\beta \int_{R_{i+1}}^{\bar{\epsilon}} J_{i+1}(x) d G(x)+\beta G\left(R_{i+1}\right)\left(V-F_{i+1}\right) \\
J_{i}(\epsilon)= & \epsilon-w_{i}(\epsilon)+\beta \int_{R_{i+1}}^{\bar{\epsilon}} J_{i+1}(x) d G(x)+\beta G\left(R_{i+1}\right)\left(V-F_{i+1}\right)
\end{aligned}
$$

The optimal productivity thresholds solve:

$$
\begin{aligned}
J_{i}^{0}\left(R_{i}^{0}\right) & =-H_{i} \\
J_{i}\left(R_{i}\right) & =-F_{i}
\end{aligned}
$$

Adding the free entry condition, $V=0$, it emerges that labor market tightness and productivity threshold are derived from the following two equations:

$$
\begin{aligned}
\frac{c}{q(\theta)} & =\sum_{i=1}^{T-1}\left[\frac{u_{i}}{u}\left(\int_{R_{i+1}^{0}}^{\bar{\epsilon}}\left[J_{i+1}^{0}(x)+H_{i+1}\right] d G(x)\right)\right] \\
R_{i} & =w\left(R_{i}\right)-F_{i}-\beta\left[\int_{R_{i+1}}^{\bar{\epsilon}} J_{i+1}(x) d G(x)-G\left(R_{i+1}\right) F_{i+1}\right] \\
R_{i}^{0} & =R_{i}+F_{i}-H_{i}
\end{aligned}
$$

Let us now examine the derivation of the two-tier wage structure. The latter is characterized by the following two sharing rules (as a result of Nash bargaining):

$$
\begin{aligned}
& \mathcal{W}_{i}^{0}(\epsilon)-\mathcal{U}_{i}=\gamma\left[J_{i}^{0}(\epsilon)+H_{i}+\mathcal{W}_{i}^{0}(\epsilon)-\mathcal{U}_{i}\right] \Rightarrow w_{i}^{0} \\
& \mathcal{W}_{i}(\epsilon)-\mathcal{U}_{i}=\gamma\left[J_{i}(\epsilon)-\left(V-F_{i}\right)+\mathcal{W}_{i}(\epsilon)-\mathcal{U}_{i}\right] \Rightarrow w_{i}(\epsilon)
\end{aligned}
$$

so that the equations for the initial and subsequent wage bargaining are (see appendix B.2 for details):

$$
\begin{aligned}
w_{i}^{0} & =(1-\gamma)\left(b-a_{i}=+\gamma\left(\epsilon+(1-\gamma) \beta p(\theta) \int_{R_{i+1}^{0}}^{\bar{\epsilon}}\left(x-R_{i+1}^{0}\right) d G(x)+H_{i}-\beta F_{i+1}\right)\right. \\
w_{i}(\epsilon) & =(1-\gamma)\left(b-a_{i}\right)+\gamma\left(\epsilon+(1-\gamma) \beta p(\theta) \int_{R_{i+1}^{0}}^{\bar{\epsilon}}\left(x-R_{i+1}^{0}\right) d G(x)+F_{i}-\beta F_{i+1}\right)
\end{aligned}
$$


which implies $R_{i}^{0}=R_{i}+F_{i}-H_{i}$.

Remaining of the proof is then straightforward by noticing that $J_{i+1}^{\prime}(\epsilon)=$ $1-\gamma$ and $J_{i}\left(R_{i}\right)=-F_{i}$ implies that $J_{i}(\epsilon)=(1-\gamma)\left(\epsilon-R_{i}\right)-F_{i}$, and similarly $J_{i}^{0}(\epsilon)=(1-\gamma)\left(\epsilon-R_{i}^{0}\right)-H_{i}$.

\section{B Wage equations derivations}

\section{B.1 Wage equations (8) and (9)}

The sharing rule (7) can be written as:

$$
-(1-\gamma) \mathcal{U}_{i}=\gamma\left[J_{i}(\epsilon)+\mathcal{W}_{i}(\epsilon)\right]-\mathcal{W}_{i}(\epsilon)
$$

From value functions (3),(5) and (6), it turns out to be that:

$$
\begin{aligned}
\gamma\left[J_{i}(\epsilon)+\mathcal{W}_{i}(\epsilon)\right]-\mathcal{W}_{i}(\epsilon)= & \gamma \epsilon-w_{i}(\epsilon)+\gamma \beta \int_{R_{i+1}}^{\bar{\epsilon}}\left[J_{i+1}(x)+\mathcal{W}_{i+1}(x)\right] d G(x) \\
& -\beta \int_{R_{i+1}}^{\bar{\epsilon}} \mathcal{W}_{i+1}(x) d G(x) \\
& -(1-\gamma) \beta G\left(R_{i+1}\right) U_{i+1}
\end{aligned}
$$

Similarly,

$$
\begin{aligned}
\gamma \beta \int_{R_{i+1}}^{\bar{\epsilon}}\left[J_{i+1}(x)+\mathcal{W}_{i+1}(x)\right] d G(x)= & \gamma \beta \int_{R_{i+1}}^{\bar{\epsilon}}\left[J_{i+1}(x)+\mathcal{W}_{i+1}(x)-\mathcal{U}_{i+1}\right] d G(x) \\
& +\gamma \beta\left[1-G\left(R_{i+1}\right)\right] \mathcal{U}_{i+1} \\
\beta \int_{R_{i+1}}^{\bar{\epsilon}} \mathcal{W}_{i+1}(x) d G(x)= & \beta \int_{R_{i+1}}^{\bar{\epsilon}}\left[\mathcal{W}_{i+1}(x)-\mathcal{U}_{i+1}\right] d G(x) \\
& +\beta\left[1-G\left(R_{i+1}\right)\right] \mathcal{U}_{i+1}
\end{aligned}
$$

Since (7) holds for each age:

$$
\gamma \beta \int_{R_{i+1}}^{\bar{\epsilon}}\left[J_{i+1}(x)+\mathcal{W}_{i+1}(x)-\mathcal{U}_{i+1}\right] d G(x)=\beta \int_{R_{i+1}}^{\bar{\epsilon}}\left[W_{i+1}(x)-\mathcal{U}_{i+1}\right] d G(x)
$$

so that (21) can be written as:

$$
\gamma\left[J_{i}(\epsilon)+\mathcal{W}_{i}(\epsilon)\right]-\mathcal{W}_{i}(\epsilon)=\gamma \epsilon-w_{i}(\epsilon)-(1-\gamma) \beta \mathcal{U}_{i+1}
$$


Incorporate this in (20) yields (8):

$$
w_{i}(\epsilon)=\gamma \epsilon+(1-\gamma)\left[\mathcal{U}_{i}-\beta \mathcal{U}_{i+1}\right]
$$

Then, let notice that the unemployed value (6), from the sharing rule (20) and the free entry (2), solves in equilibrium:

$$
\begin{aligned}
\mathcal{U}_{i} & =b+\beta\left[p(\theta) \int_{R_{i+1}}^{\bar{\epsilon}}\left(\mathcal{W}_{i+1}(x)-\mathcal{U}_{i+1}\right) d G(x)+\mathcal{U}_{i+1}\right] \\
& =b+\beta\left[p(\theta) \frac{\gamma}{1-\gamma} \int_{R_{i+1}}^{\bar{\epsilon}} J_{i+1}(x) d G(x)+\mathcal{U}_{i+1}\right] \\
& =b+\frac{\gamma}{1-\gamma} c \theta \frac{\int_{R_{i+1}}^{\bar{\epsilon}} J_{i+1}(x) d G(x)}{\sum_{i=1}^{T-1}\left(\frac{u_{i}}{u} \int_{R_{i+1}}^{\bar{\epsilon}} J_{i+1}(x) d G(x)\right)}+\beta \mathcal{U}_{i+1} \\
& =b+\frac{\gamma}{1-\gamma} c \theta \frac{\int_{R_{i+1}}^{\bar{\epsilon}}[1-G(x)] d x}{\sum_{i=1}^{T-1}\left(\frac{u_{i}}{u} \int_{R_{i+1}}^{\bar{\epsilon}}[1-G(x)] d x\right)}+\beta \mathcal{U}_{i+1}
\end{aligned}
$$

where make use of $p(\theta) / q(\theta)=\theta$ and $\int_{R_{i+1}}^{\bar{\epsilon}} J_{i+1}(x) d G(x)=(1-\gamma) \int_{R_{i+1}}^{\bar{\epsilon}}[1-$ $G(x)] d x$ by integrating by parts. Substitute out for $\mathcal{U}_{i}-\beta \mathcal{U}_{i+1}$ from this expression into $w_{i}(\epsilon)$ one gets $(9)$.

\section{B.2 Wage Bargaining with Labor Market Policy}

We let define:

$$
\begin{aligned}
& \mathcal{W}_{i}^{0}(\epsilon)=w_{i}^{0}(\epsilon)+a_{i}+\beta\left[\int_{R_{i+1}}^{\bar{\epsilon}} \mathcal{W}_{i+1}(x) d G(x)+G\left(R_{i+1}\right) \mathcal{U}_{i+1}\right] \\
& \mathcal{W}_{i}(\epsilon)=w_{i}(\epsilon)+a_{i}+\beta\left[\int_{R_{i+1}}^{\bar{\epsilon}} \mathcal{W}_{i+1}(x) d G(x)+G\left(R_{i+1}\right) \mathcal{U}_{i+1}\right]
\end{aligned}
$$

The sharing rule (18) first can be written as:

$$
-\gamma H_{i}-(1-\gamma) \mathcal{U}_{i}=\gamma\left[J_{i}^{0}(\epsilon)+\mathcal{W}_{i}^{0}(\epsilon)\right]-\mathcal{W}_{i}^{0}(\epsilon)
$$

Following the same derivation strategy as for the case without policy, we find that:

$\gamma\left[J_{i}^{0}(\epsilon)+\mathcal{W}_{i}^{0}(\epsilon)\right]-\mathcal{W}_{i}^{0}(\epsilon)=\gamma \epsilon-w_{i}^{0}(\epsilon)-(1-\gamma)\left(a_{i}+\beta \mathcal{U}_{i+1}\right)-\gamma \beta \mathcal{F}\left(2 \mathcal{A}_{1}\right)$ 
which implies by combining with (23):

$$
w_{i}^{0}(\epsilon)=\gamma\left(\epsilon+H_{i}-\beta F_{i+1}\right)+(1-\gamma)\left(\mathcal{U}_{i}-\beta \mathcal{U}_{i+1}-a_{i}\right)
$$

Then, from $J_{i}^{\prime 0}(\epsilon)=1-\gamma$ and $J_{i}^{0}\left(R_{i}^{0}\right)=-H_{i}, J_{i}^{0}(\epsilon)=(1-\gamma)\left(\epsilon-R_{i}^{0}\right)-H_{i}$ and it comes:

$$
\begin{aligned}
\mathcal{U}_{i} & =b+\beta\left[p(\theta) \int_{R_{i+1}^{0}}^{\bar{\epsilon}}\left(\mathcal{W}_{i+1}^{0}(x)-\mathcal{U}_{i+1}\right) d G(x)+\mathcal{U}_{i+1}\right] \\
& =b+\beta\left[p(\theta) \frac{\gamma}{1-\gamma} \int_{R_{i+1}^{0}}^{\bar{\epsilon}}\left[J_{i+1}^{0}(x)+H_{i+1}\right] d G(x)+\mathcal{U}_{i+1}\right] \\
& =b+\gamma p(\theta) \int_{R_{i+1}^{0}}^{\bar{\epsilon}}\left(x-R_{i+1}^{0}\right) d G(x)+\beta \mathcal{U}_{i+1}
\end{aligned}
$$

so that we derive $(20)$.

Similarly , from

$$
-\gamma F_{i}-(1-\gamma) \mathcal{U}_{i}=\gamma\left[J_{i}(\epsilon)+\mathcal{W}_{i}(\epsilon)\right]-\mathcal{W}_{i}(\epsilon)
$$

we obtain

$$
w_{i}(\epsilon)=\gamma\left(\epsilon+F_{i}-\beta F_{i+1}\right)+(1-\gamma)\left(\mathcal{U}_{i}-\beta \mathcal{U}_{i+1}-a_{i}\right)
$$

and remaining of the proof to derive $w_{i}(\epsilon)$ is straightforward.

\section{Proofs of propositions, properties and corol- laries}

\section{C.1 Proof of property 3}

Let us denote $\Psi\left(R_{i+1}, \theta\right)=\frac{G\left(R_{i+1}\right)}{[1-p(\theta)] G\left(R_{i+1}\right)+p(\theta)} \equiv \Psi_{i+1}$, so that in equilibrium $\Psi_{i} \leq \Psi_{i+1}<1$ from $R_{i+1} \geq R_{i}$. Accordingly, (1) implies that:

$$
n_{i} \gtrless n_{i+1} \Longleftrightarrow u_{i+1} \gtrless u_{i} \Longleftrightarrow \Psi_{i+1} \gtrless u_{i}
$$

For $u_{1}=1$, since $\Psi_{1}<1$, it is straightforward to see that $u_{2}<u_{1}$, hence $n_{2}>n_{1}$. Then, from $\Psi_{i+1} \geq \Psi_{i}>\Psi_{1} \forall i$, there exists an age $\tilde{T}$ which verifies $u_{\tilde{T}}=\Psi_{\tilde{T}+1}$, so that $u_{\tilde{T}+1} \geq u_{\tilde{T}} \Longleftrightarrow n_{\tilde{T}+1} \leq n_{\tilde{T}}$. 


\section{C.2 Proof of property 4}

Let combine $w_{i}\left(R_{i}\right)$ from (1) and substitute out $\int_{R_{i+1}}^{\bar{\epsilon}}[1-G(x)] d x$ for $R_{i}$ in this expression yields:

$$
w_{i}\left(R_{i}\right)=\gamma R_{i}+(1-\gamma) b+\frac{\gamma \beta(1-\gamma) p(\theta)}{1-\gamma p(\theta)}\left(b-R_{i}\right)
$$

which implies

$$
w_{i+1}\left(R_{i+1}\right)-w_{i}\left(R_{i}\right)=\left(R_{i+1}-R_{i}\right) \gamma\left(1-\beta \frac{(1-\gamma) p(\theta)}{1-\gamma p(\theta)}\right)>0
$$

\section{C.3 Proof of proposition 2}

Let us denote $\lambda_{i}$ and $\mu_{i}$ the Lagrange multiplier associated with constraints (11) and (12), optimal decision rules with respect to $R_{i+1}, \theta$ and $u_{i}, y_{i}$ are respectively given by:

$$
\begin{aligned}
\lambda_{i}= & \mu_{i} R_{i+1} \\
\sum_{i=1}^{T-1} c\left(\frac{\sum_{i=1}^{T-1} u_{i}}{T-1}\right)= & p^{\prime}(\theta) \sum_{i=1}^{T-1} u_{i}\left(\mu_{i} \int_{R_{i+1}}^{\bar{\epsilon}} x d G(x)-\lambda_{i}\left[1-G\left(R_{i+1}\right)\right]\right) \\
\lambda_{i-1}= & b-\frac{\sum_{i=1}^{T-1} c \theta}{T-1}+\lambda_{i}\left[1-p(\theta)\left[1-G\left(R_{i+1}\right)\right]-G\left(R_{i+1}\right)\right] \\
& +\mu_{i}\left[p(\theta) \int_{R_{i+1}}^{\bar{\epsilon}} x d G(x)-\int_{R_{i+1}}^{\bar{\epsilon}} x d G(x)\right] \\
\mu_{i}= & 1
\end{aligned}
$$

Substitute out for $\mu_{i}=1$, hence $\lambda_{i}=R_{i+1}$, remaining of the proof is straightforward with the definition $p^{\prime}(\theta)=[1-\eta(\theta)] q(\theta)$. 